The
Last Landscape 



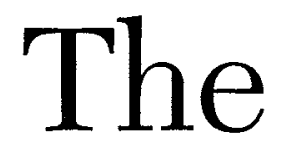

\section{Last Landscape}

\section{William H. Whyte}

Foreword by Tony Hiss

\section{$\overline{\text { PENN }}$}

University of Pennsylvania Press

Philadelphia 
Originally published 1968 by Doubleday and Company

Copyright $(\subset) 1968$ William H. Whyte

Foreword copyright $(2002$ University of Pennsylvania Press

All rights reserved

Printed in the United States of America on acid-free paper

$\begin{array}{llllllllll}10 & 9 & 8 & 7 & 6 & 5 & 4 & 3 & 2 & 1\end{array}$

Published 2002 by

University of Pennsylvania Press

Philadelphia, Pennsylvania 19104-4011

Library of Congress Cataloging-in-Publication Data

Whyte, William Hollingsworth.

The last landscape / William H. Whyte; foreword by Tony Hiss p. $\mathrm{cm}$.

Originally published: Garden City, N.Y.: Doubleday, 1968.

Includes bibliographical references and index.

ISBN 0-8122-1799-3 (pbk. : alk. paper)

1. City planning-United States. 2. Metropolitan areas-United States.

3. Greenbelts - United States. I. Title. II. Hiss, Tony

$\mathrm{HT}_{1} 67 . \mathrm{W}_{4} 82001$

$711^{\prime} \cdot 4^{\prime} 0973$

2001053435 